Review research paper

\title{
ENGLISH FOR STUDENTS OF PSYCHOLOGY AND EDUCATION: DESIGNING A TEXTBOOK
}

\author{
Ana Popović Pecić \\ Faculty of Philosophy, University of Belgrade, Serbia
}

\begin{abstract}
This paper considers some issues in designing a textbook for students of psychology and students of education enrolled in the same ESP course. These issues include balancing students' objective and subjective learning needs in the selection of real content aimed at developing necessary competences in accordance with the course objectives, as well as selecting carrier content to satisfy the needs and interests of students of both disciplines. An additional challenge involves accommodating learning needs of students with different levels of language proficiency, while also taking into account their evolving specialist knowledge. The paper then looks at the structure and content of the textbook English for Students of Psychology and Education, published by the Faculty of Philosophy, University of Belgrade.
\end{abstract}

Key words: ESP textbook design, English for psychology, English for education, learner needs, content selection

\section{INTRODUCTION}

The textbook English for Students of Psychology and Education was produced for firstand second-year students of psychology and education (pedagogy and andragogy) at the Faculty of Philosophy, University of Belgrade. English courses for students of psychology and students of education fall into the sub-category of English for Specific Purposes English for the Social Sciences (ESS), which has not received much attention "probably because it is not thought to differ significantly from more traditional humanities-based General English" (Hutchinson and Waters 1987: 16-18). Consequently, there are few, if any, textbooks on the ELT market catering for the needs of students of these disciplines, particularly when they are enrolled in the same ESP course as is the case at the Faculty of Philosophy, thus necessitating the production of in-house materials/textbooks. The textbook presented in this paper, published in 2017, was produced to meet this need.

The prerequisite for students enrolling in the first-year English course is at least eight years of studying the language during their previous schooling, and their proficiency is therefore expected to be at minimum B1 level; by the end of the second year, students' receptive and productive skills are expected to be at approximately $\mathrm{B} 2+-\mathrm{C} 1$ level. Yet in reality, their proficiency level on entering university ranges from $\mathrm{A} 2$ to $\mathrm{C} 1$, occasionally even

Submitted November $28^{\text {th }}, 2020$, accepted for publication February $15^{\text {th }}, 2021$

Corresponding author: Ana Popović Pecić. Faculty of Philosophy, University of Belgrade, Čika Ljubina.18-20, 11000 Belgrade, Serbia |E-mail: appecic@f.bg.ac.rs 
C2. These significant variations in their language ability, together with the fact that the course comprises students of two different social sciences, poses certain challenges and affects syllabus and materials design.

\section{SOME CONSIDERATIONS IN DESIGNING TEXTBOOK}

Before embarking on materials design and production, it is imperative to consider students' learning needs. At the Faculty of Philosophy, all department curricula include LSP courses in the first two years of study, the objectives of which are 'mastering the structures of general language with some elements of academic language within the different disciplines taught at the Faculty of Philosophy' and 'mastering basic language features of a particular discipline, while acquiring knowledge of more complex syntactic structures and stylistic features of general academic language and academic language of a particular discipline' for the LSP 1 and the LSP 2 courses respectively. It has been established through needs analysis that students' primary LSP need is developing the necessary competences for independent use of academic literature in English in their fields of study. For students of psychology this is indeed an immediate need, since they are expected as early as in the first year to use English-language sources in addition to Serbian-language ones when writing essays, preparing presentations, etc. For education students, on the other hand, this is a delayed, somewhat abstract need, since in the first two years of study they are not yet assigned any reading in English by their department professors. Other possible objective needs of both groups of students include listening to lectures by foreign guest speakers, and, at some point in the future, taking part in research with foreign colleagues and participating in international seminars and conferences. On the other hand, when surveyed about their subjective needs or 'wants', the majority of students cite the need to improve their speaking skills and knowledge of grammar, followed by vocabulary expansion, with reading skills a distant fourth and writing skills rarely mentioned at all.

As can be seen, there is a certain discrepancy between students' objective and subjective needs, which, unless adequately addressed by the lecturer/materials provider, could adversely affect student motivation. In view of this, the focus of the textbook has been placed on reading skills and vocabulary work in accordance with their immediate objective needs, while ensuring plenty of material and opportunities for the development of speaking skills and grammar practice; there is less emphasis on writing skills, which are lower on the list of both their immediate target needs and their wants.

Taking into account the fact that the course had to be designed for students with different specialist interests and whose language proficiency varies considerably, and in an attempt to balance students' needs and wants, the adopted approach to course design was one that falls somewhere in the middle of the continuum of course specificity, between the narrow-angled and the wide-angled course design options, i.e. geared towards the needs of a fairly specific group of learners but at the same time not highly specific in content (Basturkmen 2010: 55-59). This has also influenced the choice of topics covered in the course. Namely, as students from different disciplines are enrolled in the course, there was a need for the topics to be broader-based so as to be able to be approached from the perspective of these different disciplines (Jordan 1997: 254). Another reason for topics to be more broadly conceived rather than very specific is, once again, the important question of motivation. The piloting of different materials has borne out Dudley-Evans and $\mathrm{St}$ 
John's (1998: 10) observation that "students who are studying English because it is on the timetable of their institution [...] may be demotivated by more specific work and may be more motivated by ESP work that falls more towards the centre of the continuum' of ELT course types. The choice of topics and texts in the textbook thus represents an attempt to balance students' needs and interests, and to 'offer new ideas and information whilst being grounded in the learners' experience and knowledge" (ibid., 172); or, in other words, to provide relevant real content through relatable carrier content that will ensure students, regardless of their field of study, language level or interests, are actively engaged.

The textbook English for Students of Psychology and Education consists of six parts or thematic modules: The Family, Siblings, Schoolchildren, Gender Differences, The Teachers' Perspective and Survey Research, each comprising from three to five units. There is a progression in the sense that topics are graded from the more general to the more specific. 'The Family' is the first thematic module in the textbook because of its universal interest and relatability, allowing students, who are just starting their first year of studies and whose subject knowledge is still quite limited, to engage with the topic in a meaningful way, facilitating the transition from the general English they encountered in their previous schooling to academic English. Similarly, the topic of 'Schoolchildren' (which also covers adolescents and school) is introduced in the first half of the book (for first-year students), as it mostly relies on students drawing on their personal experience with education in their approach to the material, while 'The Teachers' Perspective', which invites students to consider education from the point of view of educators/as future practitioners in the field of education, is featured in the second half of the book (for second-year students). Admittedly, there are more units dealing with issues of education, because experience has shown that it is easier for psychology students to engage with such content than for education students to engage with highly specialized content from the field of psychology. Yet even in thematic modules which are more education-focused, issues of interest to psychology students are introduced, such as mental health issues of schoolchildren and adolescents, behavioral problems in the classroom, career counselling, etc. In addition, individual units can be expanded with supplementary materials related to the subject, posted on Moodle, Google Classroom or other platforms. Thus, to give just two examples, a unit about the adverse effects of high-stakes testing on schoolchildren's mental health can be supplemented with materials on types of assessment in education, school anxiety in children, or the effects of stress on the mental well-being of children and adults; a unit dealing with the role of school and the effects of school transition on the lives of adolescents can be supplemented with texts on identity formation in adolescence or the development of achievement attributions in childhood and adolescence (relevant for both psychology and education students). As these additional texts can be given as reading assignments to be completed between classes, they can be longer than the texts used in class, where constraints such as time available and students' attention span place limits on the length of the reading material that can be covered.

\section{UNIT STRUCTURE AND CONTENT}

The units have a recognizable pattern, but care was taken to avoid the "assembly line approach" (Hutchinson and Waters 1987: 107), where units are of uniform structure and length, each with the same type and number of exercises. The emphasis is on variety in 
terms of both type and number of exercises, which are divided into sections. At the core of each unit is a text, accompanied by pre- and post- reading activities. Each unit also includes a vocabulary and language use section with a varying number of exercises, as well as one or more of the following sections: grammar, cohesion, function, writing task and gapped text.

The length of the texts varies between 500 and 900 words, their length and the complexity of language and content gradually increasing throughout the textbook. The texts have been taken from different types of sources: university textbooks, academic books and papers, handbooks for professionals in the relevant fields, online editions of newspapers, and websites. Due to their length, book chapters and academic papers could not be reproduced in the textbook in their entirety, so excerpts were used instead; nevertheless, care was taken to ensure these excerpts had a coherent rhetorical structure and represented meaningful wholes, allowing students to identify the author's purpose and main idea and lending themselves to analysis and summarizing. Indeed, one of the important considerations in selecting texts was the possibility of their being shortened/abridged (and slightly adapted if necessary) without impairing their rhetorical structure.

The reasons for the inclusion in the textbook of academic types of text as carrier content are self-evident, but since it could be argued that newspaper prose is not immediately related to students' target situation needs, i.e. reading texts in their subject areas, it might be worth explaining why several articles from The Guardian have been included as well. The most important reason is their topicality and interest, as they provide insight into contemporary educational and mental health issues in Britain, at the same time introducing students to culture-specific concepts and vocabulary. Moreover, students are introduced to a reliable source of information on current educational and other social issues in Britain that in the future they may wish to access on their own. Articles also provide an opportunity for communicative activities such as analyzing and discussing writer's stance and the way and the order in which information, including quoted content, is presented, and their overall effectiveness. Also, since newspaper headlines tend to be catchier than the titles of book chapters or journal papers, as a pre-reading activity students can be asked to speculate on what information the article may contain based on the headline, and as a post-reading activity they can be asked to discuss the effectiveness of the original headline, as well as to come up with alternative ones. Finally, contrasting the genres of academic texts and newspaper articles can help highlight the specific features of each genre.

The texts serve as the basis for communicative activities aimed at developing students' speaking skills. Texts are preceded by pre-reading questions, and followed by reading comprehension questions as well as follow-up questions and prompts for discussion. The prereading questions serve to introduce the topic and arouse students' interest, and are designed so that every student regardless of their proficiency level is able to contribute their world knowledge and views on the topic to the discussion. Reading comprehension questions, although given after the text, can also be read beforehand, to guide students in their reading. Discussion questions and prompts aim to broaden the scope of the topic while eliciting some of the vocabulary and structures found in the text. What seems to work best regarding both pre-reading and discussion activities is if students are first asked to discuss each question in pairs or small groups before sharing their ideas with the whole class, which allows for thinking time and an exchange of views in a more relaxed setting, thus increasing the activity's communicative potential. Also, in multilevel classes, this provides students who are less confident about their speaking skills with an 
opportunity to rehearse what they might like to say when they join the whole-class discussion of the questions, and also to receive assistance from fellow students or the teacher. Other text-related activities that are not explicitly referenced in the book but are regularly practiced in class include skim reading the text in order to identify the main points, giving an oral or written summary of the text, and translating more difficult passages in order to improve accuracy of comprehension and to draw attention to certain L2 structures through comparison and contrast with L1. The gapped texts that wrap up some of the units are on the same or a closely related topic as the main text and provide an additional opportunity to practice/recycle and expand topic-related vocabulary.

In line with the previously mentioned level of specificity of the course, the vocabulary covered in the textbook is for the most part general academic and semi-technical vocabulary (highly technical or specialist vocabulary being arguably a less salient feature of the language of the social sciences than of many other fields), seeking to meet the selection criteria of frequency, utility and range (de Chazal 2014: 114), and to be relevant to the needs of both groups of students. The first activity in the "Vocabulary and Language Use' sections, 'New Vocabulary', requires students to find the words and phrases in the text that match the given definitions, as in the following excerpt from one of the texts and part of the accompanying exercise:

A child's position in the family - that is, first-born or a later-born child - can affect siblings, parents and the interactions among all family members as well as the child. Each child's experience and temperament is different, but the experience of the first-born child is unique because, at least for some period of time, a first-born child is the sole focus of parental attention. First-born children are generally more adult-orientated, helpful and self-controlled than their siblings; they also tend to be more studious, conscientious and serious, and to excel in academic and professional achievement.

Find the words in the text that correspond to the following meanings:

1. only, single (used only before a noun)

2. spending a lot of time studying or reading

3. taking care to do things carefully and correctly

4. to be very good at doing something

5. something done successfully, esp. using one's effort and skill

These definitions have the same form as those found in English advanced learner's dictionaries as they are fairly easy to understand at all levels and often provide more nuance than L1 equivalents of a word or phrase. Indeed, an important concern in any ESP course should be the development of students' dictionary skills, which are necessary if they are to become independent learners, particularly if, as in this case, their primary target need is reading academic texts. This can be achieved by helping students familiarize themselves with the various types of monolingual and bilingual dictionaries, by giving them the opportunity early on in the course to study the structure and content of entries in advanced learner's dictionaries in order to understand and make use of all the information provided, and by encouraging them to independently use online dictionary resources. Experience has shown that some aspects of dictionary use require particular attention. For example, our analyses of student L2 -> L1 translations produced in class with recourse to a dictionary suggest that a number of students tend to struggle when, on looking up a polysemous word, they have to choose the most appropriate of several meanings. The 
'Word in Focus' exercises included in some of the units seek to help students become aware of polysemy and practice choosing the right definition based on the context in which the word occurs. After completing the matching exercise, students are asked to translate the sentences into L1 and find the appropriate L1 equivalent for each of the different meanings of the given word.

\section{Word in focus: range}

Write the number of each example next to the corresponding definition.

1. They have welcomed what appears to be an increasing range of choice for individuals.*

2. Estimates of the damage range from $£ 5,000$ to $£ 7,500$.

3. Adults have a range of different motivations for selecting a course.

4. John has had a number of jobs, ranging from hairdresser to ski instructor.

5. The range of human hearing is roughly $20 \mathrm{~Hz}-20 \mathrm{kHz}$.

6. We are going to present our new range of organic hair care products.

7. These mental health problems range from depression to eating disorders.

8. Most of the students are in the 19-22 age range.

[*The first example sentence is always from the main text in the unit]

a. (noun) a number of different things of a particular type

$b$. (noun) the limits between which something varies

c. (noun) a set of products of a particular type

$d$. (verb) to vary between two particular amounts, sizes, etc.

e. (verb) to include a variety of different things in addition to those mentioned

Another area given significant attention in the book are word families. The first part of the 'Word Families' exercise is a table of word families containing words that occur in the text, and students have to complete the missing word forms by looking them up in paper or online dictionaries. Students are then given the opportunity to practice these vocabulary items in a follow-up exercise (due to space constraints, the exercises from the textbook reproduced in this paper have been abbreviated).

\section{Word families}

Complete each sentence with the appropriate word from the same word family as the one given in brackets.

1. During the argument I remained quite calm, which seemed to her even more. (angry)

2. Encoding, storage and information. (to retrieve)

3. is the essence of good design. (simple)

4. Parents with an authoritarian parenting style expect a high degree of from their children. (to comply)

5. Non-_ behavior can be a challenge for parents and caregivers of children with autism. (to comply)

The follow-up exercise can also take a slightly more challenging form of sentence rephrasing using words of a different word class from the same word family, which also entails making certain changes, thus providing students with the opportunity to practice certain collocations, the use of prepositions, transformations of adjective+noun structures into adverb + verb structures or vice versa, etc. 
Rephrase each sentence replacing the underlined word with a different part of speech from the same word family and making any other necessary changes to the structure of the sentence.

Example: May I suggest something? (noun) $\rightarrow$ May I make a suggestion?

1. Let's not assume anything before we know all the facts. (noun)

2. Modern physiology is based on Bernard's work. (noun)

3. In order to survive, animals need to be able to adapt easily. (adjective)

4. Sales have slightly increased over the last three months. (noun)

5. People who suffer from depression may benefit from physical exercise. (adjective)

'The Vocabulary and Language Use' sections also include word formation exercises, exercises for synonyms and antonyms, easily confused words, lexical groups, collocations and prepositions. These sections also look at elements of academic writing such as hedging, abbreviations, sentence connectors and reporting verbs. Some abbreviated sample exercises from different units are given below:

Word formation: compound adjectives with the form noun + past participle

1. The past participle related can combine with nouns to form adjectives that describe what something is connected with:

a. unprecedented levels of school-related anxiety, stress and mental health problems among pupils

b. big increases in school- and education-related issues

2. Some other past participles can also combine with nouns to form adjectives:

goal-directed aggression, community-supported agriculture, taxpayer-funded infrastructure projects, an employer-sponsored pension plan, a problem-centered approach, etc.

Rephrase the following phrases using noun + past participle compound adjectives:

1. a curriculum that is centered on the learner -

2. research centers funded by the government -

3. an illness that is related to stress -

4. training programs that are sponsored by the state -

5. learning that is directed towards a goal -

6. differences in performance that are related to age -

\section{Synonyms}

A. Write the adjectives in the box next to synonymous adjectives below:

enormous - vast - small - considerable - huge - substantial - modest - massive
a slight / increase etc.
a significant / increase etc.
a tremendous /_________ increase etc.


B. Rephrasing. Fill in the table:

\begin{tabular}{|l|l|}
\hline \multicolumn{1}{|c|}{ adverb + verb / verb + adverb } & adjective + noun \\
\hline $\mathrm{X}$ has gradually declined & \\
\hline & there has been a steady increase in $\mathrm{X}$ \\
\hline $\mathrm{X}$ has dropped slightly & \\
\hline & there has been a significant rise in $\mathrm{X}$ \\
\hline $\mathrm{X}$ has substantially decreased & \\
\hline
\end{tabular}

Collocations. Write the nouns from the box next to the verbs they collocate with:

$$
\text { progress - a problem - therapy - a task }
$$

1 to address / to deal with / to work through / to solve

2 to set / to assign / to get on with / to complete

3 to make / to achieve

4 to have / to go into / to receive / to undergo

'The Grammar' sections provide explanations and practice of structures that represent the "real content" of the texts in terms of grammar, so that "the relationship between meaning and form can be taught or revised in context through analysis and explanation" (Dudley-Evans and St John 1998: 75). The aim is to help students revise and build upon the knowledge of grammar they acquired at school. Thus, in large part, the grammar covered in the textbook represents a revision of structures that students are already familiar with, yet which in practice they tend to have incomplete control of, especially those whose proficiency level is below B2. These structures include verb tenses, the passive voice, the sequence of tenses, modal verbs, conditionals, comparative forms, relative pronouns and relative clauses, verb patterns with the gerund and the infinitive, etc., (in the case of verb tenses the emphasis is not so much on a thorough revision of their forms and all their possible uses as on analyzing the use of tenses in the context of the carrier texts, that is, in examples of academic writing). The fairly 'basic' area of the plural of nouns, for example, is also revisited, but only insofar as it relates to their academic needs, specifically focusing on the plural form of nouns of Greek and Latin origin. Areas that have been given particular attention are those relevant to academic writing, notably passive structures and certain types of clauses. Here are two sample exercises:

\section{Participle clauses: reduced (shortened) relative clauses}

A. Underline the participle clauses in the sentences below and then replace them with full relative clauses, as in the following examples:

a. A recent study based on a large sample survey found that one-third of adults live within 15 minutes' travel time of their mother.

$\rightarrow$... which/that was based on ...

b. They conducted a study comparing attitudes to play in three different cultures.

$$
\rightarrow \ldots \text { which/that compared attitudes to play ... }
$$

1. Teenage dating violence is essentially aggressive behaviour inflicted by a girlfriend or boyfriend in the context of an intimate relationship.

2. The researchers deliberately oversampled children living in homes in areas particularly vulnerable to violence. 
3. Overall, about two-thirds of households approached completed the interviews.

4. For violence involving injury, it was found that female victims were twice as common as male victims.

5. Psychologists working with professionals from other disciplines will note the relative infrequency of survey research in psychology.

B. Underline the relative clauses in the following sentences and then reduce them to participle clauses.

1. The children were followed up by a clinically trained research team member who was skilled in telephone crisis counselling.

2. Most psychological research is based on convenience samples which are not selected randomly and which often consist of students.

3. It is important to understand what the basis is for selecting a sample which is designed to be representative of a population.

4. Researchers who adopt a qualitative perspective seek insight rather than statistical analysis.

5. They are studying mental disorders that co-occur with drug abuse.

Sentences with double comparatives: the + [comparative form] ..., the + [comparative form] ...

Study the example from the text in which a double comparative (the + [comparative form] ..., the + [comparative form] ...) is used:

The larger the family, the greater the number of relationships there is for a child to experience.

This type of sentence with two comparative forms (adjectives, adverbs, or quantifiers) is used to say that changes in the degree of something, or changes in a particular situation, bring about changes in another thing or situation.

The word order in the two clauses is:

$\underline{\text { The }}+\underline{\text { comparative form }}+\underline{\text { subject }}+\underline{\text { verb }}, \underline{\text { the }}+\underline{\text { comparative form }}+\underline{\text { subject }}+\underline{\text { verb }}$

Note: When to be is the main verb in a clause, it can be omitted after a comparative form + noun phrase.

Write sentences with coordinated comparatives using the following ideas:

1. more children in family $\rightarrow$ less individual attention from parents

2. siblings closer in age $\rightarrow$ more shared experiences

3. smaller age difference $\rightarrow$ more competition between siblings

4. longer interval between births $\rightarrow$ parents can give children more individual attention

5. child achieves more $\rightarrow$ parental expectations become greater

The sections on cohesion focus on the use of linking words and phrases to signal textual relationships such as comparison and contrast, cause and effect, contrastive substitution and concession. In the Function sections, the focus is on various communicative functions: agreeing/disagreeing, making a suggestion, arguing for/against a position, comparing/ contrasting and discussing causal links, which are practiced through speaking and writing tasks. 


\section{COHESION: concession}

A. Study the way that concessive meaning is signalled in the following sentences:

a. She had very little work experience. Nevertheless/Nonetheless/Still/However, she got the job.

b. She had very little work experience, (and) yet she got the job.

c. Although/Even though/Though she had very little work experience, she got the job.

d. In spite of/Despite having very little work experience, she got the job.

B. Link each pair of sentences using different types of concessive links (yet; (and) yet; nevertheless/nonetheless/still/however; although/even though; in spite of/despite):

1. Childhood aggression is difficult to treat. Some intervention programs that include traditional behavior management practices have been successful.

2. A lot of teachers work up to 50 hours during the week. They often don't manage to finish their marking and have to do it over the weekend.

3. There are many differences between the US and UK higher education systems. Both provide an excellent environment for learning.

4. There have been critical reports about schools over the years. Most citizens continue to support schools and express their faith in education.

\section{FUNCTION: speculating about causal links}

Cause-and-effect relationships can be expressed by using conjunctions (because, since, etc.), verbs (to cause, to lead to, to result in, to result from, to be linked to, etc.), nouns (to be the cause/consequence/result of, etc.), adjectives (to be responsible for, to be due to, etc.) or connective adverbs and adverbial phrases (therefore, consequently, as a result, etc.) Study the following examples from the text:

1. Low achievement at tests or exams is resulting in low motivation and low self-esteem.

2. The problems are caused by increased pressure from tests/exams, [children's] greater awareness at younger ages of their own 'failure', and the increased rigour and academic demands of the curriculum.

3. The increase in diagnosis of $A D H D$ (attention deficit hyperactive disorder) has been shown to be linked to the increase in high-stakes testing.

Write sentences about the possible causes of and contributing factors to: (a) anorexia, (b) self-harming, (c) social anxiety in teenagers, (d) increasing obesity among children using the following words and phrases (don't forget to use hedges where necessary):

- to lead to, to result in, to be responsible for

- to be related to, to be linked to, to be associated with

- to be due to, to result from, to arise from, to stem from, to be caused by

- to contribute to

- to affect, to have an impact on, to be a factor in

- to account for

- to be a/the cause of, to be the origin of

- to be a/the result of, to be a/the consequence of

- as a result, as a consequence, consequently

- therefore, for this/that reason 


\section{CONCLUSION}

The textbook English for Students of Psychology and Education has been created as the core material for a two-year ESP course for students of these two fields. It is meant to be used in conjunction with other language materials, notably audio-visual materials and additional texts, and supplemented by various activities such as presentations, communicative group activities, translation activities, and writing tasks, in order to help students master essential academic language of their fields of study.

In designing the textbook, several important considerations had to be taken into account. The fact that the book has been produced to meet the needs of students of two related but distinct disciplines has necessitated an approach that is neither too narrowly specialist nor too broad, with carrier content aiming to be useful and appealing to both groups of students. Another challenge has been to try to accommodate the learning needs of students with different levels of language ability by providing a range of language content of varying complexity and topics that students can engage with regardless of their proficiency level. Finally, and most importantly, the textbook design has sought to strike a balance between students' objective and subjective needs, as well as their interests in order to enable students to develop the necessary competences in accordance with the course objectives and to maintain motivation, which is essential if effective learning is to take place.

\section{REFERENCES}

Basturkmen, H. 2010. Developing Courses in English for Specific Purposes. Basingstoke: Palgrave Macmillan.

de Chazal, E. 2014. English for Academic Purposes. Oxford: Oxford University Press.

Dudley-Evans, T., St John, M. J. 1998. Developments in English for Specific Purposes. Cambridge: Cambridge University Press.

Hutchinson, T., Waters, A. 1987. English for Specific Purposes. Cambridge: Cambridge University Press.

Jordan, R. R. 1997. English for Academic Purposes. Cambridge: Cambridge University Press. 